\title{
Executive Functions in Children with ADHD and/or Reading Difficulty
}

\author{
Estephane Enadir Lucena Duarte Pereira' ${ }^{1, *}$ (D), Carla Alexandra da Silva Moita Minervino ${ }^{1}$ (D),

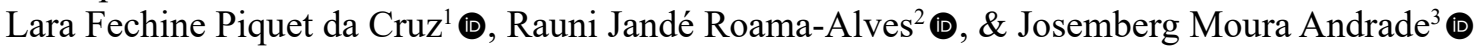 \\ ${ }^{1}$ Universidade Federal da Paraíba, João Pessoa, PB, Brasil \\ ${ }^{2}$ Universidade Federal de Rondonópolis, Rondonópolis, MT, Brasil \\ ${ }^{3}$ Universidade de Brasília, Brasilia, DF, Brasil
}

\begin{abstract}
The objective of this study was to compare the Executive Functions performance (EFs: inhibitory control, auditory and visuospatial working memory, cognitive flexibility and verbal fluency) between children with ADHD, reading difficulties (RD), comorbidity ADHD/RD and without complaints of ADHD and RD (WRD). Participated 104 children, of both sexes, aged between eight and 11 years old. The results indicated worse performance of ADHD/RD group in the majority EFs. ADHD presented better performance than DL in semantic verbal fluency. The WRD obtained better scores than the ADHD / DL and DL in practically all the evaluated EFs, but did not differ of ADHD.
\end{abstract}

KEYWORDS: executive control, attention deficit, reading

\section{Funções Executivas em Crianças com TDAH e/ou Dificuldade de Leitura}

\begin{abstract}
RESUMO - Objetivou-se comparar o desempenho em Funções Executivas (FEs: controle inibitório, memória de trabalho auditiva e visuoespacial, flexibilidade cognitiva e fluência verbal) de crianças com TDAH, com dificuldade de leitura (DL), com comorbidade entre TDAH e dificuldade de leitura (TDAH/DL) e sem queixas de TDAH e dificuldades de leitura (SDL). Participaram 104 crianças, de ambos os sexos, com idades entre 8 e 11 anos. Os resultados apontaram piores desempenhos do TDAH/DL na maioria das FEs avaliadas quando comparado aos demais grupos. O grupo de crianças TDAH apresentou melhor desempenho do que o DL em fluência verbal semântica. O SDL obteve melhores escores que o TDAH/DL e o DL em praticamente todas as FEs avaliadas, mas não se diferenciou do TDAH.
\end{abstract}

PALAVRAS-CHAVE: controle executivo, déficit de atenção, leitura

The Executive functions (EFs) involve a set of skills that, in an articulated way, give the subject the opportunity to plan, regulate and guide his or her behavior regarding the environment requirements and demands (Mourão \& Melo, 2011). This competence presents a biologically adaptive role, since the EFs are normally activated in events in which the cognitive control and the level of consciousness are required (Diamond, 2013). The cognitive flexibility, inhibitory control, working memory and verbal fluency are some of the skills of EFs (Gazzaniga et al., 2006).
Specifically, the cognitive flexibility can be defined as the ability of modified aware of perspectives or approaches to solve a problem and adapt flexibly to new requirements, rules and priorities. The inhibitory control, in turn, enables the control of attention, behavior, thoughts and emotions to replace a strong internal or external predisposition. By means of working memory, it is possible to maintain and process mentally sound or visual information, with a view to solving a problem. The verbal fluency is a basic function of language, measured by the number of words produced

*E-mail: enadirlucena@gmail.com

- Submetido: 03/10/2017; Revisado: 08/05/2018; Aceito: 15/06/2018. 
under strict conditions of time (Charchat-Fichman et al., 2011; Diamond, 2013).

Diseases such as attention deficit/hyperactivity disorder (ADHD), Reading Difficulties (DL) and their comorbidity (ADHD/DL) are associated with difficulties in EFs. This information is recognized and investigated by several authors (Bental \& Tirosh, 2007; Bolfer, 2014; Booth et al., 2013; Cozza, 2005; Cruz-Rodrigues et al., 2014; Gonçalves et al., 2013; Horowitz-Kraus, 2015, 2016; Lima et al., 2013; Lima et al., 2012; Nigg, 2001; Marzocchi et al., 2008; Saboya et al., 2007; Pennington, 2005; Pereira, 2011; Wodka et al., 2008; Wolfe, 2004; Voorde et al., 2010; Wang \& Gathercole, 2013).

Another issue investigated refers to possible differences and similarities in the EFs of these three pathologies. In a study conducted by Bental and Tirosh (2007), the authors sought to investigate these aspects, as well as linguistic skills (naming and phonological awareness), attention and reading into four groups: $\mathrm{ADHD}, \mathrm{DL}, \mathrm{ADHD} / \mathrm{DL}$ and without difficulties in reading (SDL). By means of logistic regression, the results showed that the linguistic ability of rapid serial naming, and FE of working memory impairment best explained the clinical characteristics of the group ADHD/DL.

In research performed by Voorde et al. (2010) possible differences in the EFs and linguistic skills of children distributed in four groups were investigated: ADHD, DL and ADHD/DL and SDL. For the evaluation of language, the authors evaluated the phonological processing and rapid automatic naming, and for EFs, inhibitory control and working visual and auditory memory. The results indicated that the group DL differed only from the SDL in language skills. It was also verified that in the ratings of EFs there was worse performance in inhibitory control, statistically significant, the $\mathrm{ADHD} / \mathrm{DL}$ in relation to the other groups. However, no differences were observed in memory of work among any of the intergroup comparisons.

In his turn, Horowitz-Kraus (2013) conducted a study that aimed to trace the cognitive profile of subjects with ADHD and ADHD/DL. The results showed that subjects with ADHD/DL presented lower performances in executive functions (auditory working memory, processing speed, planning, fluency and reading skills (oral reading speed, accuracy, comprehension) when compared with individuals who were affected only by the ADHD. However, these differences were not statistically significant.
The same author, Horowitz-Kraus (2015), sought again to investigate possible differences between the ADHD and ADHD/DL, by means of differential training of eight weeks in reading skills and EFs in children with both pathologies. As measures for control of EFs tests letters and symbols naming (for assessment of lexical access), look for symbols (attention), memory of digits (working memory impairment), a task for spatial perception and the "Test of Wisconsin Letters" (flexibility) were used. Regarding the reading skills, the author evaluated the accuracy, fluency and comprehension, controlling also the writing. Before the training, the evaluations showed significant differences, with worse performance of ADHD/DL in executive skills of naming and attention. There were differences in practically all reading skills. After the intervention, significant gains were observed in reading in ADHD/DL, as well as most of the EFs in both groups.

Finally, in research conducted by Marzocchi et al. (2008), it was sought to identify the executive functioning of subjects with ADHD, DL and SDL, without consideration of a comorbid group. 87 children were tested who aged between seven and 12 years, in five areas of FEs: inhibitory control, visual working memory, cognitive flexibility, planning and verbal fluency. The comparative analysis among the groups showed that the ADHD obtained worse performance than the SDL in the abilities of working memory, visual planning, flexibility and fluency. DL differed from SDL only in fluency, with worse performance. The only difference between ADHD and the SDL was in planning, with worse performance of ADHD.

From the studies presented, it is possible to realize, in general, that the ADHD/DL presented performances more leveled in EFs skills when compared to isolated diagnoses of ADHD and LD. However, it was not observed a pattern in the findings, at this moment no statistically significant differences were observed among the groups, but the differentiated skills among the groups in the various studies were not the same. In order to better elucidate the profile of the EFs functioning among these frames, the present study was proposed. The central goal was to verify possible differences in EFs (inhibitory control, working memory impairment and visuospatial, cognitive flexibility and verbal fluency) in children with ADHD, with difficulty in reading, with ADHD comorbidity with difficulty in reading and children without complaints of ADHD and reading difficulties. 


\section{METHOD}

\section{Participants}

Participated in this study 104 children, who aged between 8 and 11 years $(\mathrm{M}=9.23, \mathrm{SD}=0.87)$, and the majority was females $(\mathrm{n}=54 ; 51.9 \%)$. They were enrolled in the $3 \mathrm{rd}(\mathrm{n}$ $=31 ; 29.8 \%)$, in the 4 th $(\mathrm{n}=37 ; 35.6 \%)$ and 5 th $(\mathrm{n}=36$; $34.6 \%$ ) year of the Elementary School. It was also possible to identify their family incomes, namely: up to one minimum wage ( $\mathrm{n}=4 ; 3.8 \%$ ); between one and three minimum wages $(\mathrm{n}=85 ; 81.7 \%)$; between three and five minimum wages $(\mathrm{n}=3 ; 2.9 \%)$; between five and ten minimum wages $(\mathrm{n}=$ $8 ; 7.7 \%)$; and between 10 and 20 minimum wages $(\mathrm{n}=4$; $3.8 \%)$.
As can be seen in Table 1, the total sample was distributed into four groups: (1) students with difficulty in reading (DL); $\mathrm{n}=45 ; 43.3 \%) ;(2)$ students with ADHD and with difficulty in reading ( $\mathrm{ADHD} / \mathrm{DL}) ; \mathrm{n}=15 ; 14.4 \%$ ); (3) students with ADHD and without difficulty in reading (ADHD; $\mathrm{n}=11$; $10.6 \%$ ); and (4) students without complaints of ADHD and without difficulty in reading (SDL; $\mathrm{n}=33 ; 31.7 \%$ ). The sample showed no statistically significant differences in the variables: age $(\mathrm{F}(42)=3.531, p=0.067)$, $\operatorname{sex}(\mathrm{F}(42)=$ $0.743, p=0.394)$ and the school year $(\mathrm{F}(42)=0.716, p=$ 0.402); however, the same did not occur in relation to the variable income $(\mathrm{F}(42)=21.808, p=0.001)$.

Table 1

Description of the Sample According to Sex, Age, School Year and Family Income

\begin{tabular}{|c|c|c|c|c|c|c|c|c|}
\hline \multirow[t]{2}{*}{ Variável } & \multicolumn{2}{|c|}{$\begin{array}{c}\text { ADHD with no Reading } \\
\text { Difficulty }\end{array}$} & \multicolumn{2}{|c|}{$\begin{array}{l}\text { ADHD with Reading } \\
\text { Difficulty }\end{array}$} & \multicolumn{2}{|c|}{ Reading Difficulty } & \multicolumn{2}{|c|}{$\begin{array}{l}\text { Control Group - with } \\
\text { no Reading Difficulty } \\
\text { and no ADHD }\end{array}$} \\
\hline & $f$ & $\%$ & $f$ & $\%$ & $f$ & $\%$ & $f$ & $\%$ \\
\hline \multicolumn{9}{|l|}{ Sex } \\
\hline Female & 02 & 19 & 04 & 27 & 23 & 52 & 25 & 75 \\
\hline Male & 09 & 81 & 11 & 73 & 22 & 48 & 08 & 25 \\
\hline TOTAL & 11 & 100 & 15 & 100 & 45 & 100 & 33 & 100 \\
\hline \multicolumn{9}{|l|}{ Age } \\
\hline 8 & 03 & 27 & 05 & 33 & 10 & 22 & 05 & 15 \\
\hline 9 & 03 & 27 & 05 & 33 & 20 & 44 & 13 & 39 \\
\hline 10 & 03 & 27 & 04 & 27 & 12 & 26 & 14 & 42 \\
\hline 11 & 02 & 19 & 01 & 07 & 03 & 08 & 01 & 04 \\
\hline TOTAL & 11 & 100 & 15 & 100 & 45 & 100 & 33 & 100 \\
\hline \multicolumn{9}{|l|}{ School Year } \\
\hline $3^{\text {rd }}$ grade & 02 & 19 & 08 & 53 & 14 & 32 & 07 & 22 \\
\hline $4^{\text {th }}$ grade & 05 & 45 & 06 & 40 & 16 & 35 & 10 & 30 \\
\hline $5^{\text {th }}$ grade & 04 & 36 & 01 & 07 & 15 & 33 & 16 & 48 \\
\hline TOTAL & 11 & 100 & 15 & 100 & 45 & 100 & 33 & 100 \\
\hline \multicolumn{9}{|l|}{ Family Income } \\
\hline $\begin{array}{l}\text { Until } 1 \\
\text { minimum-salary }\end{array}$ & 00 & 00 & 02 & 13 & 02 & 04 & 00 & 00 \\
\hline $\begin{array}{l}\text { Between } 1 \text { and } 3 \\
\text { minimum-salaries }\end{array}$ & 01 & 09 & 10 & 66 & 41 & 92 & 33 & 100 \\
\hline $\begin{array}{l}\text { Between } 3 \text { and } 5 \\
\text { minimum-salaries }\end{array}$ & 01 & 09 & 01 & 07 & 01 & 02 & 00 & 00 \\
\hline $\begin{array}{l}\text { Between } 5 \text { and } 10 \\
\text { minimum-salaries }\end{array}$ & 06 & 55 & 01 & 07 & 01 & 02 & 00 & 00 \\
\hline $\begin{array}{l}\text { Between } 10 \\
\text { and } 20 \\
\text { minimum-salaries }\end{array}$ & 03 & 27 & 01 & 07 & 00 & 00 & 00 & 00 \\
\hline TOTAL & 11 & 100 & 15 & 100 & 45 & 100 & 33 & 100 \\
\hline
\end{tabular}




\section{Inclusion and Exclusion Criteria of the Sample}

For inclusion of children in all groups, the following inclusion criteria was adopted: (a) having signed a Free and Informed Consent Form (ICF) by parents/guardians and the expiry of assent by children; (b) possessing level of performance equal to or above the 25 percentile on the test of intelligence Color of Raven's Progressive Matrices (Angelini et al., 1999); (c) not having complaints of hearing problems and/or visual not corrected; (d) not having special educational needs; (e) not having emotional complaints; (f) not complaining of changes in oral language.

Specifically, for the two groups with reading difficulties, it was also adopted the inclusion criterion having performance below the average in the skills of reading comprehension and word recognition, as assessed by the instruments of 'Competency Test in the reading of Words and Pseudowords" (Seabra \& Capovilla, 2010) and Technique of Cloze (Santos, 2005). For the SDL group, the criterion was the opposite, i.e. having performance within or above the average in such instruments. Not only for this group but also for the DL, it was also adopted the criterion of not having symptoms of ADHD, according to evaluation of Swanson, Nolan and Pelham Questionnaire - IV (SNAP-IV; Mattos et al., 2006).

Whereas for the two groups who had a diagnosis of ADHD, in addition to the criteria of inclusion from "a" to "f" previously presented, the following criteria were also considered: having been diagnosed by qualified professional and who followed parameters based on Diagnostic and Statistical Manual of Mental Disorders, 5th edition (DSM5 ); in addition to the symptomatology proved by means of the scale SNAP-IV (Mattos et al., 2006), completed by teachers and parents and/or guardians. It is noteworthy that in groups with good performance in reading (ADHD and SDL) there was only the inclusion of children without a history of failure at school. The exclusion criterion for all groups was the withdrawal during the application of the instruments.

\section{Instruments}

\section{Sociodemographic Questionnaire}

The questionnaire was self-reported and presented 15 issues that discussed on the subject's sociodemographic data, such as gender, date of birth, age, education, history of fails and family income. It also contained questions relating to possible alterations in oral language, auditory or visual, special educational needs and emotional complaints.

\section{Colored Progressive Matrices test of Raven (TMPCR;Angelini et al., 1999)}

The TMPCR assesses the edutive capacity, in children aged five to 11 years, which is strictly related to the development of non-verbal intelligence (Bandeira et al., 2004). It is composed of 36 items, equally distributed in three series: A, Ab and B. The items and the series follow an increasing order of difficulty. The test classification is the result of the sum of scores (in addition to the three stages of the test, each one containing 12 items, which are, in the end, 36 points), which are converted into percentiles.

\section{Swanson, Nolan and Pelham Questionnaire - IV (SNAP-IV ; Mattos et al., 2006)}

SNP-IV is a scale used to analyze the presence, the frequency and severity of symptoms of ADHD. The IV version of SNAP was constructed on the basis of the listed symptoms (criteria) by the Diagnostic and Statistical Manual of Mental Disorders, fourth edition (DSM-IV). SNAP-IV is composed of 26 questions that must be answered by parents and/or teachers. Of the 26 items drawn up, the ones from 1 to 9 relate to symptoms of inattention; 10 to 18 , the symptoms of hyperactivity/impulsivity; and from 19 to 26 evaluate symptoms of oppositional disorder. The answers are on a scale of 4 points, which vary from 0 to 3: 0 equals to "not even a little"; 1, equal to "a little"; 2, "enough"; and 3, "others". By means of the quantitative analysis of the scores, it was possible to quantify the severity of the symptoms, instead of the simple computation of the presence of symptoms of the criterion A of DSM-IV. It should be pointed out, finally, that the criteria laid down by the SNAPIV (criteria A of the DSM-IV) are identical to the criteria of DSM-5 to identify the ADHD symptoms. This justifies the choice for this scale. SNAP-IV is a questionnaire of public domain, whose translation and adaptation to the Brazilian population were made by Mattos et al. (2006).

\section{Competency Test in the Reading of Words and Pseudowords (TCLPP; Seabra \& Capovilla, 2010)}

TCLPP aims to evaluate the processes of recognition and decoding in silent reading of isolated words, identifying which routes and reading strategies are employed by the individuals. In addition, the instrument is an adjuvant for the differential diagnosis of reading acquisition disorders. Applied individually or collectively, without a pre-determined time, the test is composed of eight items of training and 70 of test Each item is composed of an image and a written element, which can be either a word or a pseudoword. The student's role is to encircle the correct words (semantics and spelling) and cross out the incorrect ones. The response to 
the items is in a dichotomous manner, when zero is scored for each item responded in an inappropriate manner, and one for each item answered correctly. The total gross scores can vary from zero to 70 points. This score is converted into a standard-score, from standardization tables (according to age and level of education).

\section{Cloze Technique (TC; Santos, 2005)}

The TC test aims to evaluate the reading comprehension. It is composed of a task in which the fifths words of a text are abolished, and the reader should fill the spaces left the way he or she considers the most appropriate (Taylor, 1953). In a study carried out by Santos (2005), it was used the children's story "An unhappy revenge", due to being worked with children of elementary education. The text presents 100 words, where all the fifth ones were abolished from the second sentence, totaling 15 spaces to be filled in. It was corrected on the basis of the non-literal method, when the use of synonyms of words was accepted which enable the textual comprehension. The response to the items was dichotomous: for each incorrect answer, it was scored zero, and one for each correct answer. The possible number of hits of the text is 15 points.

\section{Trails Test (TT; Montiel \& Capovilla, 2007)}

The TT is subdivided into A and B; the TT evaluates the visual sustained attention, and TT-B, the cognitive flexibility. For this research, it was used the part of TT-B which is composed of a sheet with circles that contain numbers and letters and presents 1 to 12 numbers and letters from A to M. In it, the child must use dotted lines that connect, alternately, the circles with numbers and letters, following the alphabetical and numerical orders, for example: 1-A-2B-3-C. The number of hits is computed as the sum of the total number of items connected properly in sequence (varies from zero to 24 points). Example: the answer 1-A-2-B-3-C corresponds to 6 points.

\section{"Digits" Subtests of the Wechsler Intelligence Scale for children (WISC-IV; Rueda et al., 20I3)}

The WISC-IV aims to evaluate the intellectual capacity of children and adolescents ( 6 to 16 years). It is composed of 15 subtests, with five supplementary ones. In this study, it was only used the subtest of "Digits", in the direct and inverse order. The first measures the sequential auditory memory and the second the working memory capacity. It is expected that the result in reverse order is one or two points lower than the direct order (Simões, 2002). The subtest presents two numerical sequences with the same amount of numbers in each item. The direct and the reverse order have a total of 8 items each. For each item, the quantity of numbers is increased in the two sequences. In the evaluation of the subtest, it is assigned zero point if the examinee err both sequences; a point, if she answers correctly, one of the sequences; and 2 points, if she hits both sequences. The scores for the direct and inverse order are summed separately. In this sense, the maximum score for the subtest, in direct order, is 16 points and 16 points for the reverse order, therefore, 32 points in total.

\section{Blocks of Corsi (BC; Guevara et al., 20l4)}

The Blocks of Corsi are used to evaluate the visuospatial memory. It was used the computerized version of blocks of Corsi (without interference). This instrument has, in the center of the monitor, ten cubes of blue color $(3 \times 3 \mathrm{~cm})$, randomly distributed on a gray rectangular surface $(21.2 \mathrm{x}$ $17 \mathrm{~cm})$. The separation between the cubes in horizontal is 0.1 to $1.9 \mathrm{~cm}$, and vertical, 0,2 and $0.8 \mathrm{~cm}$. The performance in the task of blocks of Corsi is computed according to the number of positions remembered correctly by the examinee in each sequence. It was assigned one point to remembrance in position and in the correct order and 0.5 points for remembrance in the correct position, but out of order.

\section{Test of Five Digits (FDT; Sedó et al., 20I5)}

The FDT aims to evaluate the processing speed, attention and executive functions (inhibitory control and cognitive flexibility). It is a non-verbal instrument, which is applied individually, and that covers the age range from six to 92 years of age. The FDT is a numerical task divided into four stages: reading, counting, choice and alternation. In short, the first two steps of FDT involve automatic attentional processing and processing speed. The third and fourth stages demand attentional processing controlled and verbal fluidity (inhibitory control and cognitive flexibility). To analyze the instrument performance, it is computed the reaction time of the task, mistakes, as well as the scores of interferences (subtracting the reading time, the time of choice and this time of alternation, giving rise to the scores of inhibition and cognitive flexibility) (Oliveira et al., 2014).

\section{The Verbal Fluency Test (TFV; Charchat-Fichman et al., 20II)}

The TFV is divided into two parts, phonological fluency (TFV-F) and the semantic fluency (TFV-S). In the first, it is requested that the child verbalize the greater number of words that begin with the letter "F", "A" and " $M$ ". In the second, it is requested that the child say all animals, fruits and clothes that she can remember. For each target stimulus (letter or category), the child has a maximum time of 60 seconds for the words production. The responses were recorded with recorder for subsequent data analysis. The number of correct answers was computed by summing the number of words mentioned in each task, with scores for each target stimulus (letter or category) and for each of the two parts of the test (phonological and semantics). 


\section{Procedure}

Initially, the research project was approved by the Committee for Ethics in Research with Human Beings (Brazil) under the number of opinion 1.536.901. Then, consent for implementation of the project in schools and in a University, Hospital was sought, as well as in private clinics in the municipality that provided services to children with ADHD. Then, the FICT's were sent to the parents and/ or guardians and requested their signature, if they agreed with the participation of their children. These parents and/ or guardians were selected by convenience. Those who agreed to participate, were sent to fill the sociodemographic questionnaire and the scale SNAP-IV, the latter to also be completed by the teachers.

Afterwards, rooms were arranged for application of the instruments in the three places where the children were recruited. Three sessions were held with each one of them, of approximately 50 minutes each, at a time and date previously scheduled. In the first session, a rapport was established, and the objectives of the research were explained, in playful way, and presented the Informed Consent. In case they agree to participate, the children signed such term, and already at that same session the TMPCR was held.

In the second session, the TCLPP and Cloze Technique were applied. This assessment was of utmost importance, because it allowed the composition of four groups of analysis in this survey, in accordance with the performance in both instruments. In the third session, the tests that evaluated the EFs were applied. It was considered the TT for assessment of the construct "cognitive flexibility", Digits to "working memory impairment", blocks of Corsi for "visuospatial memory working", FDT for "inhibitory control" and TFV to "verbal fluency (phonological and semantic)". All data were analyzed using the Statistical Package for Social Sciences (SPSS) 21.0 for Windows ${ }^{\circledR}$. The level of significance adopted were $p<0.05$ (significant value), $p<0.01$ (very significant value) and $p<0.001$ (highly significant value).

\section{RESULTS}

In Table 2 it is possible to observe the averages and standard deviations obtained in each of the tests used for the evaluation of EFs agreement with each studied group. For inferential analysis, statistical tests chosen were the nonparametric ones, since the data did not meet the parameters of normality, as evidenced by the test Komogorov-Sminorv $(p<0.05)$, and the parameters of homogeneity of variance, proven by the Levene's test $(p<0.05)$. For analysis, the raw scores were used to trace the profile of executive functions in the clinical groups.

To analyze the differences between all groups, at one time, it was initially used the Kruskal-Wallis test. There were no statistically significant differences in the performance of almost all tests: TT-B $(H(3)=17.02, p=0.001)$, Digits $(H(3)=15.05, p=0.002)$, FDT $(H(3)=12.86, p=0.005)$ and TFV-F $(H(3)=18.07, p=0.001)$ and TFV-S $(H(3)=$ $12.19, p=0.007)$. Only in $\mathrm{BC}$ no difference was found $(H$ (3) $=6.37, p=0.095$ ).

In order to carry out a more detailed comparison among the groups, data were compared group to group. To do this, the Mann-Whitney test $(U)$ was used, plus the size of the effect, through the calculation of the "d Cohen" $(r)$. The reference values for this last analysis were values close to 0.2 considered small effect; values close to 0.5 considered as medium effect; values close to 0.8 considered great effect. These data can be seen in Table 3 .

Table 2

Averages and standard deviations obtained in the tests used for the evaluation of FEs, per group

\begin{tabular}{|c|c|c|c|c|c|c|c|c|}
\hline \multirow[b]{3}{*}{ Tests } & \multicolumn{8}{|c|}{ Groups } \\
\hline & \multicolumn{2}{|c|}{ DL } & \multicolumn{2}{|c|}{$\mathrm{ADHD} / \mathrm{DL}$} & \multicolumn{2}{|c|}{ ADHD } & \multicolumn{2}{|c|}{ SDL } \\
\hline & $M$ & $D P$ & $M$ & $D P$ & $M$ & $D P$ & $M$ & $D P$ \\
\hline TT-B & 10.3 & 3.9 & 8.1 & 2.4 & 12.2 & 3.9 & 12.7 & 4.3 \\
\hline Digits & 11.6 & 2.3 & 10.6 & 1.8 & 12.2 & 1.7 & 13.3 & 2.6 \\
\hline $\mathrm{BC}$ & 4.4 & 2.3 & 3.3 & 1.8 & 5 & 2.1 & 4.8 & 1.7 \\
\hline FDT & 39.8 & 20.9 & 65.1 & 26.9 & 43.2 & 16.9 & 36.4 & 13.1 \\
\hline TFV-F & 12.4 & 5.8 & 9.4 & 4.6 & 18.4 & 8.3 & 16.6 & 6.8 \\
\hline TFV-S & 21.4 & 5.3 & 23.7 & 5.8 & 29.6 & 8.9 & 25.6 & 7.02 \\
\hline
\end{tabular}

Legend:. $\mathrm{M}=\mathrm{Mean} ; \mathrm{DP}=$ standard deviation. 
Table 3

Comparisons among the groups in the tests used for the evaluation of EFs

\begin{tabular}{|c|c|c|c|c|c|}
\hline Tests & Groups & Comparative Group & $U$ & $p$ & $\mathbf{r}$ \\
\hline \multirow{6}{*}{ Test of Trails - B } & \multirow{3}{*}{ SDL } & ADHD & 217.5 & 0.33 & 0.14 \\
\hline & & $\mathrm{ADHD} / \mathrm{DL}$ & 93 & 0.001 & -0.49 \\
\hline & & DL & 997 & 0.05 & 0.29 \\
\hline & \multirow{2}{*}{ ADHD } & $\mathrm{ADHD} / \mathrm{DL}$ & 23 & 0.001 & -0.61 \\
\hline & & DL & 197 & 0.295 & -0.13 \\
\hline & $\mathrm{ADHD} / \mathrm{DL}$ & DL & 190 & 0.05 & -0.31 \\
\hline \multirow{6}{*}{ Digits } & \multirow{3}{*}{ SDL } & ADHD & 241.5 & 0.10 & 0.24 \\
\hline & & $\mathrm{ADHD} / \mathrm{DL}$ & 89 & 0.001 & -0.51 \\
\hline & & DL & 1015 & 0.05 & 0.31 \\
\hline & \multirow{2}{*}{ ADHD } & $\mathrm{ADHD} / \mathrm{DL}$ & 49.5 & 0.08 & -0.34 \\
\hline & & DL & 213 & 0.472 & -0.09 \\
\hline & $\mathrm{ADHD} / \mathrm{DL}$ & DL & 247 & 0.148 & -0.18 \\
\hline \multirow{6}{*}{ Blocks of Corsi } & \multirow{3}{*}{ SDL } & ADHD & 164 & 0.919 & 0.01 \\
\hline & & $\mathrm{ADHD} / \mathrm{DL}$ & 126.5 & 0.05 & -0.37 \\
\hline & & DL & 799.5 & 0.409 & 0.09 \\
\hline & \multirow{2}{*}{ ADHD } & $\mathrm{ADHD} / \mathrm{DL}$ & 41.5 & 0.06 & -0.36 \\
\hline & & DL & 202.5 & 0.622 & -0.06 \\
\hline & $\mathrm{ADHD} / \mathrm{DL}$ & $\mathrm{DL}$ & 238 & 0.109 & -0.20 \\
\hline \multirow{6}{*}{ Five-digit test } & \multirow{3}{*}{ SDL } & ADHD & 123.5 & 0.23 & -0.18 \\
\hline & & $\mathrm{ADHD} / \mathrm{DL}$ & 403 & 0.001 & 0.50 \\
\hline & & DL & 708.5 & 0.731 & -0.03 \\
\hline & \multirow{2}{*}{ ADHD } & $\mathrm{ADHD} / \mathrm{DL}$ & 109.5 & 0.05 & 0.37 \\
\hline & & DL & 194 & 0.499 & -0.09 \\
\hline & ADHD/DL & $\mathrm{DL}$ & 149.5 & 0.001 & -0.40 \\
\hline \multirow{6}{*}{$\begin{array}{l}\text { Verbal fluency test } \\
\text { (Phonological) }\end{array}$} & \multirow{3}{*}{ SDL } & ADHD & 155.5 & 0.78 & -0.04 \\
\hline & & ADHD/DL & 94.5 & 0.001 & -0.49 \\
\hline & & DL & 1001 & 0.05 & 0.29 \\
\hline & \multirow{2}{*}{ ADHD } & $\mathrm{ADHD} / \mathrm{DL}$ & 16 & 0.001 & -0.64 \\
\hline & & DL & 138 & 0.057 & -0.25 \\
\hline & $\mathrm{ADHD} / \mathrm{DL}$ & DL & 208.5 & 0.05 & -0.27 \\
\hline \multirow{6}{*}{$\begin{array}{l}\text { Verbal fluency test } \\
\text { (Semantics) }\end{array}$} & \multirow{3}{*}{ SDL } & ADHD & 125.5 & 0.26 & -0.17 \\
\hline & & $\mathrm{ADHD} / \mathrm{DL}$ & 209.5 & 0.39 & -0.12 \\
\hline & & DL & 1014 & 0.05 & 0.31 \\
\hline & \multirow{2}{*}{ ADHD } & $\mathrm{ADHD} / \mathrm{DL}$ & 48 & 0.144 & -0.29 \\
\hline & & DL & 102 & 0.05 & 0.35 \\
\hline & $\mathrm{ADHD} / \mathrm{DL}$ & DL & 253.5 & 0.185 & -0.17 \\
\hline
\end{tabular}

Legend: $U=$ Mann-Whitney test; $p=$ significance; $r=$ size of effect.

The results indicated that the test on the TT only there were no differences among the groups SDL and ADHD and LD and ADHD, with little effect. The following differences: when compared to the SDL and ADHD/DL (medium effect) and SDL and DL (small effect), with better performance of SDL; between ADHD and ADHD/DL (medium effect), with better performance of ADHD; and between the ADHD/ DL and DL (small effect), with better performance of DL.
In the digit test there was no difference when compared the groups ADHD and DL and ADHD/DL also with the DL, with little effect. There were differences when: compared the groups SDL and ADHD/DL (medium effect), SDL and DL (small effect), with better performance of SDL; ADHD and $\mathrm{ADHD} / \mathrm{DL}$ (small effect), with better performance of ADHD.

In $\mathrm{BC}$, the analyzes indicated that there were differences only in the following comparisons: between the groups SDL 
and ADHD/DL (small effect), with better performance of SDL; and between ADHD and ADHD/DL (small effect), with better performance of ADHD.

In FDT there was also only difference among the following groups: SDL and ADHD/DL (medium effect), with better performance of SDL; ADHD and ADHD/ DL (medium effect), with better performance of ADHD; and between the ADHD/DL and DL (small effect), with better performance of DL. It is important to note that the calculation of performance in this test was performed from the time spent in performing the task, in this way, the larger the averages, the worst the performances.

In the TFV-F there were only differences in two comparisons between the SDL and ADHD and between
ADHD and LD, with small effects. There was difference when: compared to the SDL and ADHD/DL groups (medium effect) and SDL and DL (small effect), with better performance of SDL; ADHD and ADHD/DL (medium effect), with better performance of ADHD; and between the ADHD/DL and DL (small effect), with better performance of DL.

In the TFV-S there were different results of the TFV-F. It was found that in the majority of comparisons, there was no difference, only when compared the SDL and DL groups (small effect), with better performance of SDL; and ADHD and LD (small effect), with better performance of ADHD.

\section{DISCUSSION}

The objective of this research was to verify if there would be differences in the profile of the EFs of children with ADHD, reading difficulty, ADHD comorbidity with difficulty in reading and children without complaints of $\mathrm{ADHD}$ and reading difficulties. It is worth remembering that the EFs here investigated were: cognitive flexibility (inferred by the TT), working memory impairment (by the Test digits), visuospatial working memory (BC test), inhibitory control test (FDT) and verbal fluency test (TFV).

According to the results, it was observed that the group of ADHD/DL presented worse performance in the instruments, generally, when compared to the other groups. It is possible to observe lower mean of that group to analyze the Table 2, with some of them being significant (Table 3). Only in the Semantic Verbal Fluency there was better average than the one obtained in the DL, but without significant difference. From now on, it is possible to say that the comorbid condition possibly favored larger losses in cognitive abilities, most of which the disorders in isolation would favor. To some extent, these results were expected according to previous studies, which indicated deficits in most EFs investigated in this group when compared to the groups without comorbidities (Horowitz-Kraus, 2013; Voorde et al., 2010).

On the other hand, in a study conducted by Bental and Tirosh (2007) it was found that the ADHD/DL group only differed from the other groups in auditive working memory. The authors concluded, anyhow, that such a framework deserves care, because it presents a distinctive profile and should be diagnosed with great caution. HorowitzKraus (2015) reaffirms this placement and indicates that this condition would be distinct from the ADHD without comorbidities, with losses in cognitive functions more frequently and with unique challenges. In order to reinforce this idea, in the present study, it was found that the losses of ADHD/DL in relation to ADHD were higher, with a significant statistical difference in practically all EFs (only in semantic verbal fluency such a difference was not observed ).
Not only the ADHD/LD and ADHD would be groups with distinct cognitive characteristics, but the DL group as well (Voorde et al., 2010). The results found here only showed a significant difference between the ADHD and the DL in semantic verbal fluency, with worse performance of DL. This finding can be explained by what the literature has stated: there would be only one individual functional deficit, as in FE, responsible for understanding the complex nature of these disorders, there would be, for example, in ADHD, also attention and motor deficits, and in DL, verbal skills deficits, more strongly linked to the phonological processing, which would also be characteristic to these conditions (Pennington, 2005). Therefore, it is also suggested the hypothesis: would the most evident losses in EFs in the ADHD group/DL be more present, because there would be the union of all these functional deficits in one clinical picture?

In any case, this fact becomes especially interesting in clinical and evaluative contexts, because it demonstrates that both conditions can present similar profiles in EFs, but at the same time also present specific characteristics to each one of them, such as, for example, the performance demoted in verbal tasks by part of the DL.

When comparing the three clinical groups with the SDL, it was found out that the ADHD/DL and DL presented lower performances on all the Fes tasks, even though some of them were not significant. These results were expected and highlighted by several studies that performed this type of comparison (Bental \& Tirosh, 2007; Booth et al., 2013; Cimadon, 2012; Lima et al., 2012; Voorde et al., 2010; Wang \& Gathercole, 2013). However, no significant differences were found between the SDL with the ADHD group in most EFs evaluated. Such information was not expected in accordance with the literature, which indicates often losses in such skills in this disorder when compared to a group of children without behavioral and learning complaints (Capovilla et al., 2007; Gonçalves et al., 2013, Wolfe, 2004). 
Interestingly, in a study performed by Wodka et al. (2008) similar results were found. The authors compared the performance of children with no complaints of inattention/ hyperactivity with those of children with ADHD in executive skills of inhibitory control (Stroop Test), planning (Tower of London), attention and flexibility (TT) and verbal fluency (TFV, phonological and semantic). These instruments were part of a battery called Delis Kaplan Executive Function
System (D-KEFS). Their results indicated no differences among the groups in any of these skills. The authors concluded that there would be possibly problems in the instrument used, which was not sensitive to differentiate the clinical pictures (there was frequently ceiling effect in the studied groups.) It is possible that, in the present study, the instruments were not sensitive either.

\section{FINAL CONSIDERATIONS}

In principle, it was possible to see that the ADHD group/DL showed losses in skills of EFs characteristic of the two disorders, but more intense than when these conditions independently. This fact becomes relevant, since it demonstrates that this clinical picture must be carefully assessed to ensure that there is effective interventions and specific.

In turn, the ADHD differed from the DL only on the ability of semantic verbal fluency, with worse performance of DL. Such data would indicate that the disorders, when present independently, may have many similarities in the performance in FEs, but at the same time, specificities, as in language skills. This fact becomes very relevant when thought the differential diagnosis of both conditions.

Interestingly, when the groups were compared to the SDL, only the ADHD presented no differences with this group. It was suggested the possibility of the instruments used have not been sensitive to the differentiation of both groups, since the literature strongly suggests that there are differences between these skills when performed such a comparison.

In relation to the limitations of the study, the first to be cited is regarding the groups DL and ADHD/DL. In such groups a thorough evaluation was not performed in order to verify if they had other diagnoses, such as, for example, dyslexia. Future studies, with the same methodological design of this research involving the analysis of such disorders, will be a great gain to the area.

In addition, a good part of the references used here differentiated nomenclature used to set up their groups, such as: reading disorder, learning difficulties, reading difficulties, among others. It is verified that there is some confusion in the international literature on methodological definition and diagnosis of their groups, which often can interfere in the generalization of the results. It is expected that there is better control on the definition of such groups in future studies of the area.

As a proposal of continuity, it is suggested the use of others and a greater number of instruments for measurement of EFs. It is suggested validated and recognized instruments, as well as those which also involve language skills, in order to identify even more characteristics among the investigated groups.

The type of study here performed also favors the investigation of criterion validity on the instruments. Showing details of operating conditions that seem to be forthcoming, as well as proposing correction tables that contemplate them, facilitate the differential diagnosis and a consequent better prognosis.

\section{REFERENCES}

Angelini, A. L., Alves, I. C. B., Custódio, E. M., Duarte, W. F., \& Duarte, J. L. M. (1999). Matrizes Progressivas Coloridas de Raven: Escala especial. Manual. Centro Editor de Testes e Pesquisa em Psicologia.

Bandeira, D. R., Alves, I. C. B., Giacomel, A. E., \& Lorenzatto, L. (2004). Matrizes progressivas coloridas de Raven - Escala especial: Normas para Porto Alegre. Psicologia em Estudo, 9(3), 479-486. https://doi.org/10.1590/S1413-73722004000300016.

Capovilla, A. G. S., Assef, E. C. S., \& Cozza, H. F. P. (2007). Avaliação neuropsicológica das funções executivas e relação com desatenção e hiperatividade. Avaliação Psicológica, 6(1), 51-60. http://pepsic.bvsalud.org/scielo.php?script=sci_arttext \&pid=S1677-04712007000100007.

Charchat-Fichman, H., Oliveira, R. M., \& Silva, A. M. (2011). Performance of Brazilian children on phonemic and semantic verbal fluency tasks. Dementia Neuropsychologia, 5(2), 78-84. https://doi.org/10.1590/S1980-57642011DN05020004.

Bental, B., \& Tirosh, E. (2007). The relationship between attention, executive functions and reading domain abilities in attention deficit hyperactivity disorder and reading disorder: a comparative study. Journal of Child Psychology and Psychiatry, 48(5), 455-463. https://doi.org/10.1111/j.14697610.2006.01710.x

Bolfer, C. P. M. (2014). Avaliação neuropsicológica das funções executivas e da atenção antes e depois do uso do metilfenidato em crianças com transtorno de déficit de atenção/ hiperatividade (Doctoral dissertation). Faculdade de Medicina de São Paulo, São Paulo, Brasil.

Booth, J. N., Boyle, J. M. E., \& Kelly, S. W. (2013). The relationship between inhibition and working memory in predicting 
children's reading difficulties. Journal of Research in Reading, 37(1), 84-101. https://doi.org/10.1111/1467-9817.12011

Cozza, H. F. P. (2005). Avaliação das funções executivas em crianças e correlação com atenção e hiperatividade (Master thesis). Universidade São Francisco, Itatiba, Brasil.

Cruz-Rodrigues, C., Barbosa, T., Toledo-Piza, C. M. J., Miranda, M. C., \& Bueno, O. F. A. (2014). Neuropsychological Characteristics of Dyslexic Children. Psicologia Reflexão e Critica, 27(3), 539-546. https://doi.org/http://dx.doi. org/10.1590/1678-7153.201427315.

Diamond, A. (2013). Executive functions. Annual Review of Psychology, 64, 135-68. https://doi.org/10.1146/annurevpsych-113011-143750.

Diamond, A., \& Ling, D.S. (2016). Conclusions about interventions, programs, and approaches for improving executive functions that appear justified and those that, despite much hype, do not. Developmental Cognitive Neuroscience, 18, 34-48.

Doyle, C. (2017). Executive Function (EF) in Dyslexia: Examining an EF profile associated with dyslexia and comorbid dyslexia$A D H D$ and exploring the near and far transfer effects of $E F$ Training in Dyslexia Alone (Doctoral dissertation). Dublin City University.

Gonçalves, H. A., Mohr, R. M., Moraes, A. L., Siqueira, L. S., Prando, M. L., \& Fonseca, R. P. (2013). Componentes atencionais e de funções executivas em meninos com TDAH: Dados de uma bateria neuropsicológica flexível. Jornal Brasileiro de Psiquiatria, 62(1), 13-21. https://doi.org/10.1590/ S0047-20852013000100003.

Guevara, M. A., Sanz-Martin, A., Hernández-González, M., \& Sandoval-Carrillo, I. K. (2014). CubMemPC: prueba computadorizada para evaluar la memoria a corto plazo visuoespacial con y sin distractores. Revista Mexicana de Ingenieria Biomédica, 35(2), 175-186. http://www.rmib.somib. org.mx/pdfs/Vol35/No2/5.pdf.

Horowitz-Kraus, T. (2013). Can the error monitoring system differentiate ADHD from ADHD with reading disability? Reading and executive dysfunction as reflected in error monitoring. Journal of Attention Disorders, 22(10), 889-902. https://doi.org/10.1177/1087054713488440.

Horowitz-Kraus, T. (2015). Differential effect of cognitive training on executive functions and reading abilities in children with ADHD and in children with ADHD comorbid with reading difficulties. Journal of Attention Disorders, 19(6), 515-526. https://doi.org/10.1177/1087054713502079.

Lima, R. F., Azoni, C. A. S., \& Ciasca, S. M. (2013). Atenção e funções executivas em crianças com dislexia do desenvolvimento. Psicologia em Pesquisa, 7(2), 208-219. https://doi.org/10.5327/Z1982-1247201300020009

Lima, R. F., Travaini, P. P., Azoni, C. A. S., \& Ciasca, S. M. (2012). Atención sostenida visual y funciones ejecutivas en niños con dislexia de desarrollo. Anales de Psicologia, 28(1), 66-70. http://www.redalyc.org/pdf/167/16723161008.pdf.

Marzocchi, G. M., Oostrlaan, J. Zuddas, A. Cavolina, P., Geurts, H., Redigolo, D., Vio, C., \& Sergeant, J. A. (2008). Contrasting deficits on executive functions between ADHD and reading disabled children. Journal of Child Psychology and Psychiatry, 49(5), 543-552. https://doi.org/10.1111/j.14697610.2007.01859.x.

Mattos, P., Pinheiro, M. A. S., Rohde, L. A., \& Pinto, D. (2006). Apresentação de uma versão em português para uso no Brasil do instrumento MTA-SNAP-IV de avaliação de sintomas de transtorno do déficit de atenção//hiperatividade e sintomas de transtorno desafiador e de oposição. Revista de Psiquiatria do Rio Grande do Sul, 28(3), 290-297. https://doi.org/10.1590/ S0101-81082006000300008.

Menghini, D., Finzi, A., Benassi, M., Bolzani, R., Facoetti, A., Giovagnoli, S., \& Vicari, S. (2010). Different underlying neurocognitive deficits in developmental dyslexia: A comparative study. Neuropsychologia, 48(4), 863-872.

Montiel, J. M., \& Capovilla, A. G. S. (2007). Teste de Trilhas - parte B. In A. G. S. Capovilla, \& F. C. Capovilla. (Eds), Teoria e pesquisa em avaliação neuropsicológica (pp. 94-95). Memnon.

Mourão, C. A. M., \& Melo, L. B. R. (2011). Integração de três conceitos: Função executiva, memória de trabalho e aprendizado. Psicologia: Teoria e Prática, 27(3), 309-314. http://www.scielo.br/pdf/ptp/v27n3/06.pdf.

Nigg, J. T. (2001). Is ADHD a disinhibitory disorder? Psychological Bulletin, 127, 571-598. https://www.ncbi.nlm.nih.gov/ pubmed/11548968.

Oliveira, T. D., Malloy-Diniz, L. F., Magalhões, S., Costa, D. S., Lacerda, S. R., Querino, E. H. G., \& Paula, J. J. (2014). Propriedades psicométricas do Teste dos Cinco Dígitos para o contexto brasileiro: estudo preliminar com a população adulta (Conference paper). Universidade Federal de Minas Gerais, Belo Horizonte, Brasil.

Pennington, B. F. (2005). From single to multiple deficit models of developmental disorders. Cognition, 101, 385-413. https:// doi.org/10.1016/j.cognition.2006.04.008.

Pereira, A. P. P. (2011). Desenvolvimento de funções executivas em crianças sem domínio da linguagem escrita e relação com desatenção e hiperatividade (Master thesis). Universidade Presbiteriana Mackenzie, São Paulo, Brasil.

Poljac, E., Simon, S., Ringlever, L., Kalcik, D., Groen, W. B., Buitelaar, J. K., \& Bekkering, H. (2010). Impaired task switching performance in children with dyslexia but not in children with autism. The Quarterly Journal of Experimental Psychology, 63(2), 401-416.

Rueda, F. J. M., Noronha, A. P. P., Sisto, F. F., Santos, A. A. A., \& Castro, N. R. (2013). Escala Wechsler de inteligência para crianças - WISC-IV. Casa do Psicólogo.

Saboya, E., Saraiva, D., Palmini, A., Lima, P., \& Coutinho, G. (2007). Disfunção executiva como uma medida de funcionalidade em adultos com TDAH. Jornal Brasileiro de Psiquiatria, 56(1), 30-33. https://doi.org/10.1590/S0047-20852007000500007.

Santos, A. A. A. (2005). O Teste de Cloze como instrumento de avaliação da compreensão em leitura (Technical report). Universidade São Francisco, Bragança Paulista, SP, Brasil.

Seabra, A. G., \& Capovilla, F. C. (2010). Teste de competência de leitura de palavras e pseudopalavras (TCLPP). Memnon.

Sedó, M., Paula, J. J, \& Malloy-Diniz, L. F. (2015). O Teste dos Cinco Dígitos. Hogrefe.

Simões, M. R. (2002). Utilizações da WISC-III na avaliação neuropsicológica de crianças e adolescentes. Paidéia, 12(23), 113-132. https://doi.org/10.1590/S0103-863X2002000200009.

Taylor, W. L. (1953). Cloze procedure: a new tool for measuring read-ability. Journalism Quarterly, 30, 415-433. http://journals. sagepub.com/doi/pdf/10.1177/107769905303000401.

Voorde, S. V. D., Roeyers, H., Verté, S., \& Wiersema, J. R. (2010). Working memory, response inhibition, and within-subject variability in children with attention-deficit/ hyperactivity disorder or reading disorder. Journal of Clinical and Experimental Neuropsychology, 32(4), 366-379. https://doi. org/10.1080/13803390903066865. 
Wang, S., \& Gathercole, S. E. (2013). Working memory deficits in children with reading difficulties: memory span and dual task coordination. Journal of Experimental Child Psychology, 115, 188-197. https://doi.org/10.1016/j.jecp.2012.11.015.

Whiteside, D., Kealey, T., Semla, M., Luu, H., Rice, L., Basso, M. \& Roper, B. (2016). Verbal fluency: Language or executive function measure? Applied Neuropsychology Adult, 23(1), 29-34.
Wodka, E. L., Mostofsky, S. H., Prahme, C., Larson, J. C. G., Loftis, C., Denckla, M. B., \& Mahone, E. M. (2008). Process examination of executive function in ADHD: sex and subtype effects. The Clinical Neuropsychologist, 22(5), 826-841. https://doi.org/10.1080/13854040701563583.

Wolfe, E. M. (2004). Executive function processes: Inhibition, working memory, planning and attention in children and youth with attention deficit hyperactivity disorder (Master thesis). Texas A\&M University, Texas, USA. 